\title{
Coagulation tests or standardized questionnaire, which is better as a predictor of bleeding? A prospective study among children before tonsillectomy and/ or adenoidectomy
}

Muhamed Masalha ${ }^{1,3^{*}}$, Ari DeRowe², Salim Mazzawi ${ }^{1}$, Tzvi Chen ${ }^{1}$, Rami Ghanayim', Roee Landsberg ${ }^{3}$ and Ariel Koren ${ }^{4}$

\begin{abstract}
Objective: The value of pre-operative coagulation testing for adenotonsillar surgery is controversial. The purpose of this study was to evaluate the role of routine coagulation tests and a standardized questionnaire in children before tonsillectomy and/or adenoidectomy.

Results: A total of 143 children were prospectively enrolled in the study between 2013 and 2017, 81 males (56.6\%) and 62 females (43.4\%), age range 1 to 18 years (median age 5 years). Eighteen bleeding events were documented, three of them required treatment in the operating room. Abnormal coagulation tests were not associated with higher odds of bleeding after surgery. Higher risk of bleeding $(p=0.01)$ was associated with an abnormal standardized medical questionnaire.
\end{abstract}

Keywords: Bleeding, Coagulation tests, Tonsillectomy, Adenoidectomy, Questionnaire

\section{Introduction}

Tonsillectomy and/or adenoidectomy (T/AD) is a frequently performed procedure in children. 300,000 surgeries are carried out annually in the United States [1]. The main indications for T/AD are obstructive sleep disturbances (mainly in younger children), and recurrent tonsillitis (often in older children) [2].

In $\mathrm{T} / \mathrm{AD}$ surgery the tonsillar tissue is dissected in the plane between the tonsillar capsule and the pharyngeal muscles. This can be performed with different

\footnotetext{
*Correspondence: masalha.muhamed@gmail.com

1 Deptartment of Otolaryngology Head and Neck Surgery, Emek Medical Center (affiliated with The Ruth and Bruce Rappaport School of Medicine, Technion Institute of Technology, Haifa), Yitzhak Rabin Boulevard 21, 1834111 Afula, Israel

Full list of author information is available at the end of the article
}

techniques; cold dissection, monopolar or bipolar electrocautery, radiofrequency and coblation [3].

Bleeding is probably the most important, serious, and discussed complication associated with T/AD. The risk for post T/AD bleeding is $1-5.7$ percent by some reports [4] and $2-7 \%$ by others $[5,6]$. Some studies report even higher and wider range $[7,8]$. Immediate post-operative bleeding, occurring in the first $24 \mathrm{~h}$ after surgery, can be attributed to inadequate operative hemostasis [1]. Delayed bleeding, occurring later is thought to be the result of sloughing a covering eschar or loosened vessel tie $[1,7]$.

In candidates for $\mathrm{T} / \mathrm{AD}$ there is a consensus for screening for a personal and familial history of bleeding and is typically performed during pre-operative evaluation. However, the utility of pre-operative routine coagulation

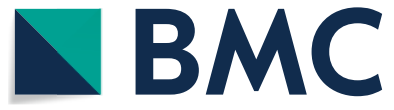

(c) The Author(s) 2020. This article is licensed under a Creative Commons Attribution 4.0 International License, which permits use, sharing, adaptation, distribution and reproduction in any medium or format, as long as you give appropriate credit to the original author(s) and the source, provide a link to the Creative Commons licence, and indicate if changes were made. The images or other third party material in this article are included in the article's Creative Commons licence, unless indicated otherwise in a credit line to the material. If material is not included in the article's Creative Commons licence and your intended use is not permitted by statutory regulation or exceeds the permitted use, you will need to obtain permission directly from the copyright holder. To view a copy of this licence, visit http://creativeco mmons.org/licenses/by/4.0/. The Creative Commons Public Domain Dedication waiver (http://creativecommons.org/publicdomain/ zero/1.0/) applies to the data made available in this article, unless otherwise stated in a credit line to the data. 
tests is controversial [1]. Both the British Committee for standards in Hematology 2008 and the American Academy of Otolaryngology-Head and Neck surgery did not recommend standard pre-operative coagulation tests $[1,9]$. Recommendations against performing standardized coagulation laboratory test are supported by a large body of literature $[4-6,9,10]$. However, several articles show a contradicting opinion, suggesting that performing those tests pre-operatively may be beneficial in predicting potential bleeding and coagulopathies $[1,7,11,12]$.

Preoperative bleeding history questionnaires (POBQ) have been developed by several researchers [4]. Such questionnaires aim to standardize the pre-operative patients' history evaluation before $\mathrm{T} / \mathrm{AD}$, avoiding the loss of important data that may predict bleeding tendency and to improve uniformity of the pre-operative evaluation process among caregivers.

In this study we propose to further determine the need for pre-operative coagulation tests before T/AD surgery in children. We also try to evaluate the value of a standardized pre-operative questionnaire, alone or with routine coagulation tests in predicting the risk to bleed after T/AD.

\section{Main text \\ Methods}

Children of both genders, less than 18 years of age who had been scheduled for T/AD between January 2013 and December 2017 at Emek Medical Center were included prospectively. One of their parents or legal custodians signed informed consent. Only patients who underwent surgery were included in this study.

The main indications for surgery were obstructive sleep disturbances or recurrent tonsillitis. Ages ranged from 1 to 18 years. A recent pre-operative platelet counts and routine blood coagulation tests including prothrombin time (PT), PT ratio, activated partial thromboplastin time (aPTT), aPTT ratio and PT international normalized ratio (INR) results were reviewed according to the routine protocols used in our department. Abnormal results were defined as any result falling beyond the normal scale values; for aPTT a prolonged time above $37^{\prime \prime}$, for INR above 1.2, for PT above 13.6" and for platelets count below $150,000 \times 10^{9} / \mathrm{dl}$.

A standardized pre-operative bleeding history questionnaire was given to every participant parent. The questionnaire consisted of three groups of questions; the first group dealt with the child's personal history of bleeding, the second with family history, and the third group of questions dealt with general medication history. Any positive response in any of the above mentioned parts was defined as a positive questionnaire.
All abnormal coagulation studies were reviewed by the pediatric hematologist before approving the surgery. After reviewing children with positive questionnaire we decided to operate them without further evaluation.

All patients underwent surgery using the same technique, monopolar diathermy.

At least 2 weeks after surgery, patients' parents were called, and a second questionnaire was completed during this phone call. The second questionnaire reviewed the followings issues: bleeding after surgery, time of bleeding, and specific treatment given. Post-operative bleeding was defined by any amount of fresh nasal or oral blood after surgery observed by a caregiver.

Data was collected and summarized, with continuous variables presented as means and standard deviation along with median and range, and categorical data as number and percent. Comparison of the two groups was made by Chi square or Fisher's exact test where appropriate for categorical data and by the Mann-Whitney test for continuous data. Relative risk (RR) ratio and 95\% confidence interval (CI) were computed to assess the rate of bleeding. Statistical significance was set at $\mathrm{p}$ (probability value) $<0.05$. Data analysis was performed using SPSS version 21 and Winpepi.

\section{Results}

A total of 143 children were enrolled in the study, 81 males (56.6\%) and 62 females (43.4\%). Age ranged between 1 and 18 years with a mean age of $5.6 \pm 3.4$ years old $[$ median $=5$ years].

Eighteen out of 143 children were documented to have bleeding after surgery (12.6\%). Three of them required treatment in the operating room. On average the bleeding occurred after $4.9 \pm 5.9$ days [median $=4$ days]. Ten of the bleeders had mild bleeding that stopped spontaneously at home and they either didn't receive any medical care or were reassured by a primary physician. Eight children were examined in the emergency room and in five of these cases the bleeding stopped spontaneously; all these children were admitted for observation and released in good condition the following day. The remaining three children $(2.1 \%)$ underwent surgical intervention to control bleeding and were released after a short period of observation in hospital.

Out of 143 patients, 111 (81.0\%) had normal coagulation screening tests and $26(19.0 \%)$ had abnormal results. In 6 children coagulation screening tests were not available. However, the tests were reported to be normal by a parent or by a primary doctor. Eighteen patients bled after surgery, with 13 (11.7\%) having normal coagulation screening tests and five (19.2\%) abnormal screening test (four had mild prolonged aPTT ranged from 37.4" to $38.7^{\prime \prime}$ and one had a mild abnormal PT of $\left.13.7^{\prime \prime}\right)$. The 
bleeding rate between patients having a normal or abnormal coagulation screening test was not statistically significant $\left(x^{2}=1.04\right.$, Fisher's exact $\mathrm{p}=0.34$, RR:1.09; 95\% CI 0.90-1.33; Table 1). Table 2 presents the results of the coagulation tests. There were no statistically significant differences between these tests in children who bled and those who did not bleed although the children who did not bleed tended to have higher platelet count than their counterparts $(\mathrm{Z}=1.73 \mathrm{p}<0.08)$.

Out of 143 children, $20(14.0 \%)$ had abnormal positive questionnaire during the pre-operative evaluation. Six of those children suffered from a bleeding event (30.0\%). In the group of $123(86.0 \%)$ children with a negative questionnaire, there were $12(9.8 \%)$ bleeders. This difference was statistically significant $\left(\chi^{2}=6.41, p=0.011\right)$ (Table 1$)$. The rate of a child who had an abnormal positive questionnaire during the pre-operative evaluation to bleed were more than 3 times that of children who had a normal questionnaire (RR: 3.08 ; 95\% CI 1.30-7.26).

In only four patients both the pre-operative coagulation tests and the questionnaire were abnormal. Of them two patients $(50 \%)$ suffered from a bleeding event. When both the questionnaire and the coagulation tests were abnormal, the risk of bleeding was not found to be statistically significantly higher. $\left(x^{2}=5.25\right.$, Fisher's exact $\mathrm{p}=0.08$; RR: 6.94; 95\% CI 1.04-46.27) (Table 3).

Out of the three patients that required intervention in the operating room for bleeding control, one patient had both pre-operative abnormal coagulation tests (only mild prolonged $\mathrm{PT}^{\prime \prime}$ of 13.7) and positive questionnaire. The other two patients had normal pre-operative evaluation.

\section{Discussion}

The preoperative evaluation before T/AD surgeries is important and should emphasize bleeding risks.
Table 2 Coagulation tests of children who bled vs. children who didn't

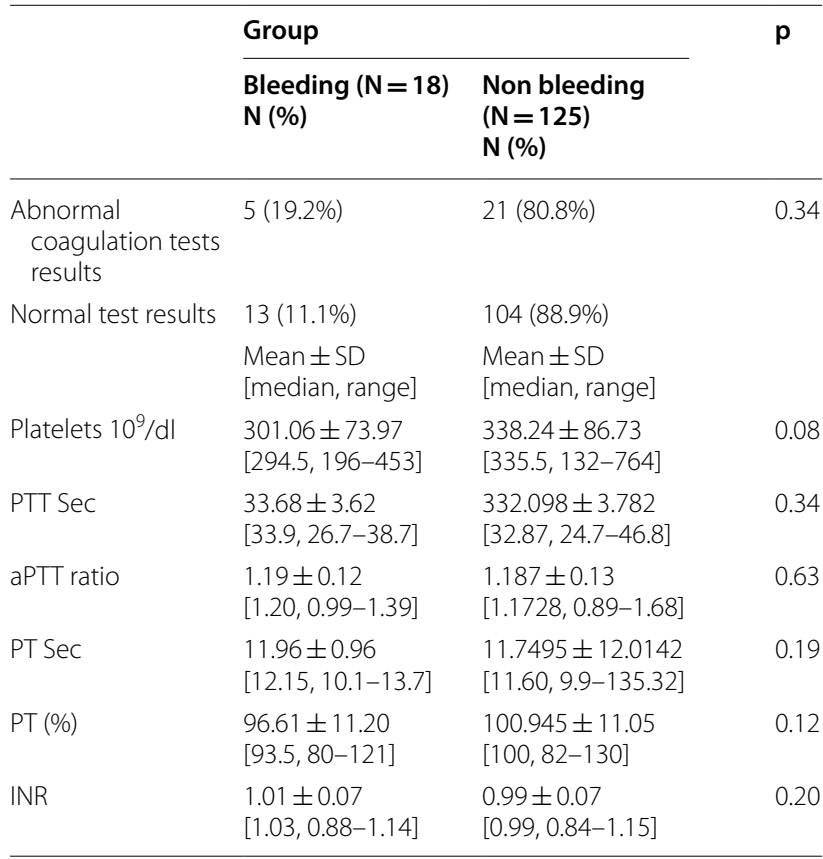

$N$ number, $S D$ standard deviation, $p$ probability value

When we compared, qualitatively and quantitatively, the coagulation tests' results between the group of bleeders and non-bleeders, neither abnormal results nor the value of the results showed a significant difference between the groups (Tables 1 and 2). The rate of bleeders in patients with normal coagulation tests was $11.6 \%$, while in the group with abnormal blood tests was $19.2 \%$, these higher rates in the bleeding group were not statistically significant, but can still give a feeling that coagulation tests though not sensitive in predicting bleeding, may have additional value and should not be initially

Table 1 The impact of abnormal coagulation tests on bleeding

\begin{tabular}{|c|c|c|c|c|c|}
\hline Risk factor & $\begin{array}{l}\text { Total }(\mathrm{N}=137) \\
\mathrm{N}(\%)\end{array}$ & $\begin{array}{l}\text { Bleeding }(\mathrm{N}=18) \\
\mathrm{N}(\%)\end{array}$ & $\begin{array}{l}\text { No Bleeding }(\mathrm{N}=119) \\
\mathrm{N}(\%)\end{array}$ & $p$ & $\mathrm{RR}(95 \% \mathrm{Cl})$ \\
\hline $\mathrm{PTT}>37 " \mathrm{~s}$ & $19(14.6)$ & $4(21.1)$ & $15(78.9)$ & 0.27 & 1.76 \\
\hline $\mathrm{PTT} \leq 37^{\prime \prime} \mathrm{s}$ & $111(85.4)$ & $14(12.6)$ & $97(87.4)$ & & $(0.66-4.72)$ \\
\hline INR above 1.2 & $0(0.0)$ & $0(0.0)$ & $0(0.0)$ & - & - \\
\hline PT $>13.6^{\prime \prime} \mathrm{s}$ & $6(4.6)$ & $1(16.7)$ & $5(83.3)$ & $>0.99$ & 1.04 \\
\hline $\mathrm{PT} \leq 13.6^{\prime \prime} \mathrm{s}$ & $125(95.4)$ & $17(13.6)$ & $114(86.4)$ & & $(0.72-1.49)$ \\
\hline $\mathrm{Plt}<150 \times 10^{9} / \mathrm{dl}$ & $1(0.7)$ & $0(0.0)$ & $1(100.0)$ & $>0.99$ & $0.42^{*}$ \\
\hline $\mathrm{Plt} \geq 150 \times 10^{9} / \mathrm{dl}$ & $136(99.3)$ & $16(11.8)$ & $118(88.2)$ & & $(0.02-7.45)$ \\
\hline Abn results & $26(19.0)$ & $5(19.2)$ & $21(80.8)$ & 0.34 & 1.09 \\
\hline Normal results & $111(81.0)$ & $13(11.7)$ & $98(88.3)$ & & $(0.90-1.33)$ \\
\hline
\end{tabular}

$N$ number, $R R$ risk ratio, $C l$ confidence interval, $P$ It platlets, $A b n$ abnormal

*Adjusted ratio with 0.5 added to each cell 
Table 3 Comparison between the bleeding group and the non-bleeding group

\begin{tabular}{|c|c|c|c|c|}
\hline & Bleeding $(\mathrm{N}=18)$ & No bleeding $(\mathrm{N}=125)$ & p value & $\mathrm{RR}(95 \% \mathrm{Cl})$ \\
\hline Questionnaire positive & $6(33.3 \%)$ & $14(11.2 \%)$ & 0.01 & $3.08(1.30-7.26)$ \\
\hline $\begin{array}{l}\text { Questionnaire \& coagulation abnor- } \\
\text { mal }\end{array}$ & $2(11.1 \%)$ & $2(1.6 \%)$ & 0.08 & $6.94(1.04-46.27)$ \\
\hline \multicolumn{5}{|l|}{ Gender } \\
\hline Male & $13(72.2 \%)$ & $68(54.4 \%)$ & 0.15 & $1.33(0.96-1.84)$ \\
\hline \multirow[t]{2}{*}{ Female } & $5(27.8 \%)$ & $57(45.6 \%)$ & & \\
\hline & $\begin{array}{l}\text { Mean } \pm \text { SD } \\
\text { [median; range] }\end{array}$ & $\begin{array}{l}\text { Mean } \pm \text { SD } \\
{[\text { median; range] }}\end{array}$ & & \\
\hline Age (years) & $\begin{array}{l}6.9 \pm 4.3 \\
{[5.5 ; 3-18]}\end{array}$ & $\begin{array}{l}5.4 \pm 3.2 \\
{[5.0 ; 1-17]}\end{array}$ & 0.25 & $1.11^{*}(0.98-1.26)$ \\
\hline
\end{tabular}

$N$ number, $R R$ risk ratio, $C l$ confidence interval, $A D$ adenoidectomy, $T O N$ tonsillectomy, $S D$ standard deviation

*Odds ratio estimate of RR

invalidated. We agree with the opinion of many researchers that it may not be necessary to perform these tests in every child prior to T/AD [4-6, 9, 10], however, we recommend these tests in any child with a positive medical history or questionnaire. When both the questionnaire and the coagulation tests are positive, pediatric hematologist consultation should be considered. Coagulation tests may further ascertain the normal risk for bleeding in some cases and may unveil some hidden conditions that are worth managing before surgery. Children with complex medical conditions such as obesity, and craniofacial abnormalities or syndromes, are to be considered for performing coagulation tests before surgery. These children are at increased risk for surgical or anesthetic complications [13], and any further post-operative reintervention may carry a higher general risk.

Seeking relevant personal and family history prior to $\mathrm{T} / \mathrm{AD}$ surgery is widely accepted. In our study, obtaining medical history before surgery, using standardized questionnaire, could predict higher risk for bleeding after $\mathrm{T} /$ AD surgeries in children, therefore, further evaluation of these children should be considered. Standardization of medical history using a dedicated questionnaire has the advantage of standardizing the assessment process among various medical personnel and avoids omitting portions of the relevant history. Our impression is that both the caregivers and the patients' family are comfortable using this questionnaire, in a relatively short time and with ease. This tool is concise, cheap, noninvasive, and facilitates acquiring a complete history and physical examination.

Four children had both abnormal coagulation test and abnormal questionnaire, two of them (50\%) bled $(\mathrm{p}=0.08$, Table 3$)$ and one required treatment in the operating room. Although not statistically significant, this could be due to a small sample size. Probably, a combined abnormal questionnaire along with abnormal coagulation tests improves the ability to predict the risk to bleed better than each alone, we recommend hematological consultation for these patients before surgery.

The overall bleeding rate in this study was $12.5 \%$. The reported rate in the literature is usually between 2 and $7 \%[5,6]$, other reports suggest a wider range of up to $20 \%[7,8]$. At a glance, it seems that the bleeding rate in our study is higher than that reported, but other factors should be taken into consideration in this analysis. Firstly, it is a prospective study with a fixed post-operative follow-up; every bleeding event, even though very minor is reported and documented. In our study, in most children who were reported as bleeders (10 out of 18), the bleeding had stopped spontaneously and they were followed at home. Five children presented to the emergency room and were admitted to hospital for observation with no intervention. Only 3 patients (2.1\%) returned to the operating room for control hemorrhage. This rate is consistent with the literature. Secondly, there is a wide variation in the reported rate of bleeding in literature (2 to 20\%), which arises mainly from different size and age structures of patient's population, various indications for surgery, studies type, and different duration of post-operative follow up [14]. Therefore, the bleeding rate in our study is acceptable.

In conclusion, in this study we show that routine preoperative coagulation tests before T/AD surgeries in children is not necessary and should be reserved for special risk population. Pre-operative abnormal standardized medical questionnaire was found to accurately predict children with higher risk to bleed after T/AD surgeries and should routinely be used in the evaluation process before surgery. When the questionnaire reveals a risk, further workup including coagulation tests and/or pediatric hematology consultation should be considered. 


\section{Limitations}

One of our major limitations in this study was the small populations size of the children who bled, of the children with abnormal questionnaire and or abnormal coagulation tests, which affected our ability to accurately reflect significance. Moreover, it would be beneficial if we had performed complete coagulation tests analysis including clotting factors analysis for every child with abnormal questionnaire, something that we could not do in this study and should be addressed in future studies.

\section{Abbreviations \\ T/AD: Tonsillectomy and/or adenoidectomy; POBQ: Preoperative bleed- ing history questionnaires; PT: Prothrombin time; aPTT: Activated partial thromboplastin time; INR: PT international normalized ratio; RR: relative risk; $\mathrm{Cl}$ : Confidence interval; p: Probability value.}

\section{Authors' contributions}

MM: Major contribution in the design of the work, acquisition, analysis, and interpretation of data, drafted the main part of the work and critically revised it. AD: have made substantial contributions to the conception and critically reviewed the article. SM, RL: have made substantial contributions to the interpretation of data and critically reviewed the article. TC, RG: have made substantial contributions to data acquisition and analysis. Critically reviewed the article. AK: major contribution in the design of the work, acquisition, analysis, and interpretation of data and critically reviewed the article. All the Authors have approved the submitted version (and any substantially modified version that involves the author's contribution to the study) and have agreed both to be personally accountable for the author's own contributions and to ensure that questions related to the accuracy or integrity of any part of the work. All authors read and approved the final manuscript.

\section{Funding}

None.

\section{Availability of data and materials}

The datasets used and/or analysed during the current study available from the corresponding author on reasonable request.

\section{Ethics approval and consent to participate}

This study was approved by Emek Medical Center local institutional review board (IRB), and was conducted according to Helsinki declarations with complete consent. Committee reference number: IORG0006222. One of the child's parents or legal custodians signed informed consent.

\section{Consent for publication}

Not applicable.

\section{Competing interests}

The authors declare that they have no competing interests.

\section{Author details}

${ }^{1}$ Deptartment of Otolaryngology Head and Neck Surgery, Emek Medical Center (affiliated with The Ruth and Bruce Rappaport School of Medicine,
Technion Institute of Technology, Haifa), Yitzhak Rabin Boulevard 21, 1834111 Afula, Israel. ${ }^{2}$ Deptartment of Otolaryngology Head and Neck Surgery, Pediatric Otolaryngology, Tel Aviv Sourasky Medical Center (affiliated with Sackler School of Medicine, Tel Aviv University), 6 Weizmann Street, 64239 Tel Aviv, Israel. ${ }^{3}$ Otolaryngology, Head and Neck Surgery, Assuta Medical Center (affiliated with Ben Gurion University-Faculty of Medicine, Beer Sheva), 20 Habarzel St, Ramat Hachayal, 69710 Tel Aviv, Israel. ${ }^{4}$ Pediatric Hematology Unit, Emek Medical Centre (affiliated with The Ruth and Bruce Rappaport School of Medicine, Technion Institute of Technology, Haifa), Yitzhak Rabin Boulevard 21, 1834111 Afula, Israel.

Received: 12 February 2020 Accepted: 13 March 2020

Published online: 24 March 2020

\section{References}

1. Koshkareva YA, Cohen M, Gaughan JP, Callanan V, Szeremeta W. Utility of preoperative hematologic careening for pediatric adenotonsillectomy. Ear Nose Throat J. 2012;91(8):346-56.

2. Parker NP, Walner DL. Trends in the indications for pediatric tonsillectomy or adenoidectomy. Int J Pediatr Otorhinolaryngol. 2011;75(2):282-5.

3. Oomen KP, Modi VK, Stewart MG. Evidence-based practice pediatric tonsillectomy. Otolaryngol Clin North Am. 2012:45(5):1071-81.

4. Licameli GR, Jones DT, Santosuosso J, Lapp C, Brugnara C, Kenna MA. Use of preoperative bleeding questionnaire in pediatric patient who undergo adenotonsillectomy. Otolaryngol Head Neck Surg. 2008;139(4):546-50.

5. Burk CD, Miller L, Handler SD, Cohen AR. Preoperative history and coagulation screening in children undergoing tonsillectomy. Pediatrics. 1992;89:691-5.

6. Krishna P, Lee D. Post-tonsillectomy bleeding: a meta analysis. Laryngoscope. 2001;111(8):1358-61.

7. Myssiorek D, Alvi A. Post-tonsillectomy hemorrhage: an assessment of risk factors. Int J Pediatr Otorhinolaryngol. 1996;37(1):35-43.

8. Spektor Z, Saint-Victor S, Kay DJ, Mandell DL. Risk factors for pediatric post-tonsillectomy hemorrhage. Int J Pediatr Otorhinolaryngol. 2016;84:151-5

9. Cooper JD, Smith KJ, Ritchey AK. A Cost-Effectiveness analysis of coagulation testing prior to tonsillectomy and adenoidectomy in children. Pediatr Blood Cancer. 2010;55(6):1153-9.

10. Eisert S, Hovermann M, Bier H, Göbel U. Preoperative screening for coagulation disorders in children undergoing adenoidectomy (AT) and tonsillectomy (TE): does it prevent bleeding complications? Klin Padiatr. 2006;218(6):334-9.

11. Bolger WE, Parsons DS, Potempa L. Preoperative hemostatic assessment of the adenotonsillectomy patient. Otolaryngol Head Neck Surg. 1990;103(3):396-405.

12. Bhasin N, Parker RI. Diagnostic outcome of preoperative coagulation testing in children. Pediatr Hematol Oncol. 2014;31(5):458-66.

13. De Luca Canto G, Pachêco-Pereira C, Aydinoz S, et al. Adenotonsillectomy complications: a meta-analysis. Pediatrics. 2015;136(4):702-18.

14. Stuck BA, Götte K, Windfuhr JP, Genzwürker $H$, Schroten $H$, Tenenbaum T. Tonsillectomy in Children. Dtsch Arztebl Int. 2008;105(49):852-60.

\section{Publisher's Note}

Springer Nature remains neutral with regard to jurisdictional claims in published maps and institutional affiliations. 